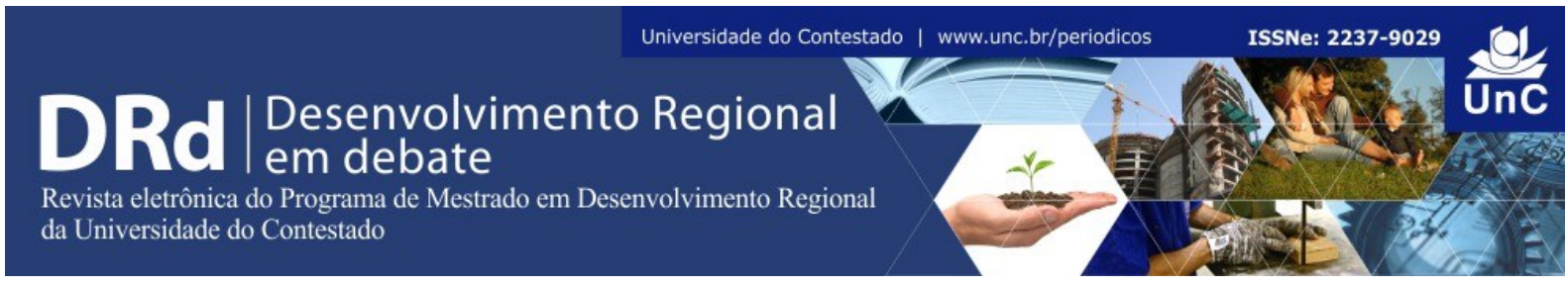

\title{
A CONTRIBUIÇÃO DA ABORDAGEM DO DESENVOLVIMENTO TERRITORIAL NA TRANSFORMAÇÃO DAS PRÁTICAS DE EXTENSÃO RURAL ${ }^{1}$
}

\author{
Serinei Cesar Grígolo ${ }^{2}$ \\ Paulo Roberto Cecconi Deon ${ }^{3}$ \\ José Marcos Froehlich ${ }^{4}$
}

\begin{abstract}
RESUMO
O objetivo desse artigo é analisar a construção teórica da abordagem territorial e sua possível contribuição para a implementação da política pública de ATER no Brasil. Para isso retoma abordagens conceituais sobre territórios e faz um exercício de inferência às práticas de ATER num diálogo crítico entre autores, visando contribuir com o repensar permanente da Extensão Rural. É efetuada análise do discurso em documentos referentes à PNATER, CNATER e ANATER, buscando também a contribuição de alguns estudos que abordam a atividade dos extensionistas. Esta reflexão serve como ponto de partida para constatar que predominantemente a ação extensionista tem permanecido setorial. Também se evidencia a existência de descompasso entre o discurso e a prática. Nesse sentido, embora documentos que orientam a ATER considerem aspectos de coletividade, participação, sustentabilidade, os indícios apontam mais para a adoção da noção de território como dado e menos para a de território construído.
\end{abstract}

Palavras-chave: Agricultura Familiar. Desenvolvimento Territorial. ATER. Participação. Políticas Públicas.

\section{THE TERRITORIAL DEVELOPMENT APPROACH'S CONTRIBUTION TO THE TRANSFORMATION OF RURAL EXTENSION PRACTICES}

\begin{abstract}
The purpose of this paper is to analyze the theoretical construction of the territorial approach and its possible contribution to the implementation of public policy ATER in Brazil. For this upturn conceptual approaches territories and an inference exercise to ATER practices in a critical dialogue between authors, in order to contribute to the ongoing rethinking of Agricultural Extension. Discourse analysis is performed on documents relating to PNATER,

\footnotetext{
${ }^{1}$ Este artigo é uma ampliação de texto apresentado no $51^{\circ}$ Congresso da SOBER, 2013, em Belém, em 2013.

${ }^{2}$ Mestre, doutorando pelo programa de Pós-Graduação em Extensão Rural, Universidade Federal de Santa Maria - RS. Professor da Universidade Tecnológica Federal do Paraná, câmpus Dois Vizinhos. Dois Vizinhos, PR. Brasil. E-mail: serineicgrigolo@utfpr.edu.br

${ }^{3}$ Mestre, doutorando pelo programa de Pós-Graduação em Extensão Rural, Universidade Federal de Santa Maria - Santa Maria - RS. Prof. IF Farroupilha Campus SVS. São Vicente do Sul, Rio Grande do Sul, Brasil. E-mail: paulo.deon@iffarroupilha.edu.br

${ }^{4}$ Pós-Doutor em Antropologia Social pela Universidad de Sevilla, Doutor em Ciências Sociais pela UFRRJ. Professor Associado do Departamento e atual Coordenador do PPG em Extensão Rural da UFSM, Santa Maria - RS. Brasil. E-mail: jmarcos.froehlich@gmail.com
}

DRd - Desenvolvimento Regional em debate (ISSNe 2237-9029)

v. 5, n. 2, p. 109-126, jul./dez. 2015. 
CNATER and ANATER also seeking the contribution of some studies that address the activity of extension. This reflection serves as a starting point to see that predominantly the extension action has been sector. Also highlights the existence of gap between theory and practice. In this sense, although documents that guide the ATER consider aspects of community, participation, sustainability, evidence pointing towards the adoption of the territory notion for granted and less for the built territory.

Keywords: Family Farming. Territorial Development. ATER. Participation. Public policy.

\section{INTRODUÇÃO E PROBLEMÁTICA}

O tema que envolve esse artigo diz respeito, por um lado, à construção teórica entorno da abordagem territorial do desenvolvimento e por outro, no plano prático, a efetividade desta "nova" proposta enquanto discurso e ação governamental, a qual fica mais evidente na retórica instituída pelas próprias ações públicas, à exemplo da $\mathrm{PNATER}^{5}$, da $1^{\mathrm{a}} \mathrm{CNATER}^{6} \mathrm{e}$ da ANATER ${ }^{7}$.

No plano teórico, o enfoque localista de desenvolvimento assume pressupostos em que preponderam aspectos sociais sobre aspectos econômicos e o rural é valorizado por características histórico-espaciais próprias. Nesse contexto surge a abordagem territorial do desenvolvimento, a qual ressalta a necessidade de diferentes abordagens multidisciplinares que contribuam para a compreensão dos processos de desenvolvimento como específicos às diferentes características sócio-político-econômicas de cada sociedade (ABRAMOVAY, 2007a; BRANDÃO, 2007).

A abordagem territorial passa a representar um conjunto de características idealizadas para o processo de desenvolvimento, além de fazer parte da retórica em discursos governamentais. Entretanto, vários autores têm apontado limites dessa abordagem que vão desde a falta de consistência da própria construção teórica (ABRAMOVAY, 2007a; BRANDÃO, 2007) como também relacionadas com sua incorporação enquanto política pública, a exemplo de Favareto (2010, p. 312) que denuncia uma "[...] incorporação "por adição' dos novos temas, sem a devida mudança institucional capaz de sustentar a inovação que ela deveria significar".

Segundo Favareto (2006) a abordagem territorial veio à tona a partir da erosão das

5A PNATER - Política Nacional de Assistência Técnica e Extensão Rural constitui-se como um marco na trajetória da Extensão Rural Brasileira. Trata-se da institucionalização de um conjunto de princípios (desenvolvimento rural sustentável, universalização dos serviços de Ater, equidade nas relações de gênero, e outros) resultantes de um profundo processo de reflexão sobre os impactos da ação extensionista orientada pelo modelo de modernização da agricultura. Tais princípios representam não somente o rompimento com uma ideologia simbolizada pelo difusionismo e pela agricultura convencional, mas representam também propostas de caminhos para superar as problemáticas que levaram à crise o modelo anterior (FIGUEIREDO, 1984; CAPORAL e COSTABEBER, 2000).

$61^{\text {a }}$ Conferência Nacional sobre Assistência Técnica e Extensão Rural na Agricultura Familiar e Reforma Agrária, que ocorreu em 2012.

7Agência Nacional de Assistência Técnica e Extensão Rural, criada em maio de 2014. 
bases que sustentavam o termo Desenvolvimento Rural, principalmente por estarem demasiadamente focados nos aspectos agrícolas e agrários, afeitos à dimensão setorial. Segundo o autor, a relação entre sociedade e natureza provoca um dos primeiros "deslocamentos" da abordagem, saindo da produção exclusiva de bens primários para uma multiplicidade de possibilidades, a exemplo da "[...] valorização e aproveitamento das amenidades naturais, a conservação da biodiversidade e a utilização de fontes renováveis de energia" (p. 191). Ainda, o rural passa a ser visto como espaço heterogêneo, que estabelece diferentes formas de integração com o urbano, não sendo mais possível de tomar como dois polos opostos. Por esta perspectiva, os territórios rurais passam a ser atrativos e produtores de rendas não rurais. Portanto é um discurso que busca enunciar princípios de desenvolvimento que estão além da dimensão econômica e para além dos limites geográficos entre rural e urbano, assim como também representa uma inovação emergente do discurso científico em relação à visão agrária do desenvolvimento rural.

No plano das políticas públicas a Extensão Rural Brasileira, a partir da PNATER 2004, reestrutura-se institucionalmente e pauta-se por novas diretrizes, que a orientam exclusivamente para agricultores familiares em todos os seus segmentos, utilizando-se de metodologias participativas e de tecnologias de base ecológica, visando o desenvolvimento sustentável. No entanto, a abordagem territorial do desenvolvimento rural não chega a se configurar como orientação central, aparecendo mais como uma dimensão escalar junto aos níveis nacional, estadual, regional e municipal. Abramovay $(2007 \mathrm{~b}$, p. 17) aponta que "[...] o processo de desenvolvimento das regiões rurais envolve um desafio de natureza territorial e não setorial [...]", como preveem as diretrizes para o Sistema Brasileiro de Assistência Técnica e Extensão Rural (BRASIL/MDA, 2004a). O autor vê nessas diretrizes uma abordagem essencialmente setorial.

[...] não é admissível que a extensão rural limite-se a preocupar-se com a agricultura ou com as atividades que se encontram à jusante da agricultura (agroindustrialização) quando seu desafio básico deveria ser o de contribuir para o desenvolvimento rural [...] a grande maioria dos pobres rurais não vive fundamentalmente da agricultura $\mathrm{e}$ dificilmente terá na agricultura a base decisiva de mudança de sua condição social [...] as oportunidades para melhorar suas condições de vida podem estar na agricultura ou fora dela. $\mathrm{O}$ processo de envelhecimento da população economicamente ativa na agricultura é uma expressão clara da natureza não agrícola da pobreza rural [...] (ABRAMOVAY, 2007b, p. 2).

Ainda:

A ruralidade não é composta necessariamente por agricultores que, eventualmente,
exercem outras atividades mais ou menos tributárias da agricultura. Ela é
multisetorial e nesta heterogeneidade, muitas vezes, está o caminho para ampliar a
geração de oportunidades que, com tanta frequência, a agricultura não pode mais
oferecer [...] a insistência do documento da ATER [o autor refere-se à PNATER] em
servir exclusivamente os agricultores familiares exprime bem os problemas que
derivam de uma abordagem setorial e não territorial do desenvolvimento
(ABRAMOVAY, 2007b, p. 3,6 ).

O autor refere-se ao documento da PNATER 2004, no entanto a reflexão pode ser também aplicada ao documento da $1^{\text {a }}$ CNATER, que acentua a exclusividade às minorias, como pode ser observado no documento.

Nas ações de Ater reconhecer as peculiaridades da agricultura familiar (conforme nota 1) e dos grupos étnicos, no que se refere a sua forma de organização social, de

DRd - Desenvolvimento Regional em debate (ISSNe 2237-9029) 
produção e comercialização, de relacionamento com os elementos da natureza e de gestão de seus territórios, [...] (BRASIL/MDA, 2012a, p. 56).

A referida nota 1 trata das minorias ${ }^{8}$ constantemente citadas no documento, denotando uma necessidade de atuação bastante específica e setorial, mesmo que muitas vezes, no documento referido, cite-os como territórios de identidade.

O autor ainda critica o documento (PNATER) quando destina a ATER para o combate à pobreza: “[...] é preciso distinguir políticas públicas que garantem 'direitos' (saúde, educação, transferência direta de renda) daquelas a que a extensão rural, em princípio, se dedica, que são políticas de desenvolvimento" (ABRAMOVAY, 2007b, p. 5).

Certamente pode-se discordar do teor de suas críticas ou mesmo da concepção de desenvolvimento territorial, principalmente na importância que dá ao setor privado para os "[...] processos virtuosos de geração de renda que possam contribuir para reduzir a pobreza e melhorar as condições ambientais das regiões em que atuam [...]" (ABRAMOVAY, 2007b, p. 8), onde há razões de sobra para desconfiar dessa boa vontade, no entanto, deixa elementos que fundamentam a afirmação de que a política de ATER tem permanecido, sobretudo, setorial.

A ATER brasileira vem passando por mudanças metodológicas significativas, tomando por base suas diretrizes. Estas mudanças foram influenciadas pelas críticas ao difusionismo e às formas positivistas de ler a realidade, ao mesmo tempo em que expressa uma oposição contra as estruturas de poder dominante. Aponta para uma ATER orientada ao desenvolvimento rural sustentável, mimetizado na proposta da agroecologia; para os vulneráveis, para os povos tradicionais, para a integração das políticas públicas, para multidimensionalidade e multifuncionalidade, para a inovação tecnológica, para o ensino, para agricultura urbana, para mulheres, para os biomas, para serviços ambientais, para fortalecer o controle social das políticas públicas, para a diversificação, para a vigilância sanitária, para a comunicação alternativa, para a juventude, para certificação, para o etnodesenvolvimento, para economia feminista e, finalmente, para o desenvolvimento territorial (BRASIL/MDA, 2012a). Assim, podemos perguntar: as inconsistências com que a abordagem territorial se apresenta na retórica das políticas públicas sugerem questionamentos quanto à efetividade dessa abordagem nas práticas extensionistas?

Diante desse contexto, o objetivo desse artigo é pontuar questões de ordem prática que têm sido apontadas, corriqueiramente, como limitantes para uma ação extensionista com enfoque territorial. $\mathrm{O}$ alinhamento teórico metodológico da ANATER com antigos processos de difusão de tecnologias, assim como foi o Treino e Visita, reacende a discussão. O aparente abandono da abordagem territorial são constatações que merecem ser aprofundadas, pois firmam práticas setoriais, bastantes criticadas pela abordagem do desenvolvimento territorial.

A orientação metodológica deste trabalho tem base na análise do discurso (SILMERVAN, 2009) conduzida a partir de uma perspectiva dialógica entre o arcabouço 8As quais abarcariam “[...] a diversidade dos seguintes segmentos: agricultura familiar tradicional, camponeses,
acampados, assentados da reforma agrária, povos indígenas, povos de terreiro e ciganos/as, quilombolas,
açorianos, atingidos por barragens, mineradoras e hidrelétricas, extrativistas, seringueiros/as, quebradeiras de
coco, fundos de pasto, faxinalenses, pescadores/as artesanais, ribeirinhos/as, aquicultores familiares, caiçaras,
marisqueiros/as, retireiros/as, torrãozeiros/as, geraizeiros/as, vazanteiros/as, pomeranos/as, pantaneiros/as,
caatingueiros/as, dentre outros/as" (BRASIL/MDA, 2012a, p. 2). 
teórico que sustenta a perspectiva territorial do desenvolvimento e documentos referentes à PNATER, CNATER e ANATER, além de alguns estudos que abordam a atividade extensionista, utilizados como referência para a análise das práticas de ATER. Como dimensões analíticas, o caminho da investigação examina limites na teoria sobre desenvolvimento territorial e a normatividade nas políticas públicas, principalmente do Ministério do Desenvolvimento Agrário e da Secretaria de Desenvolvimento Territorial; também examina limites na promoção do desenvolvimento territorial e em sua incorporação ao nível normativo na ATER e, por fim, examina limites à incorporação do desenvolvimento territorial na prática da ATER.

Além desta introdução, a estrutura do texto conta com a próxima seção onde o desenvolvimento territorial é abordado a partir de elementos que caracterizam sua construção teórica e as contribuições para interpretar a ATER sob esta perspectiva. A seção seguinte analisa a política e a efetivação da prática de ATER enquanto perspectiva territorial. $\mathrm{Na}$ última seção são pontuadas as principais considerações e recomendações de estudos que as análises permitem.

\section{A ATER SOB A PERSPECTIVA DO DESENVOLVIMENTO TERRITORIAL: ALGUMAS CONSIDERAÇÕES TEÓRICAS}

A abordagem territorial do desenvolvimento apresenta duas origens bem distintas. Uma primeira orientação está fortemente relacionada aos aspectos econômicos envolvidos no processo, e cujas experiências italianas dos distritos industriais são um dos exemplos mais representativos. Os sistemas produtivos localizados (distritos industriais constituídos por pequenas e médias empresas) contribuíram para o surgimento da importância do fator territorial, segundo Cazella (2012), embora ressaltando aspectos como competitividade, empreendedorismo, crescimento econômico, tal modelo tem sido referenciado pela literatura como um caso de desenvolvimento localizado merecedor de reflexões. Uma segunda orientação, embora inicialmente com baixo grau de articulação e de menor hegemonia, abrange a ênfase em eventos sociopolíticos contemporâneos diversos que vieram a contribuir para o fortalecimento da ideia segundo a qual os atores locais devem assumir o desenvolvimento de sua região, ou seja, é justamente num clima econômico de crise, " [...] de descentralização do poder do Estado, de efervescência por parte dos movimentos sociais e da existência de uma geração que aprendeu na escola a dar valor aos potenciais locais, que o pensamento do desenvolvimento territorial foi sendo construído" (CAZELLA, 2012, p. 28), atribuindo lugar estratégico aos atores locais para o enfrentamento da crise econômica.

O que se entende daí referente à construção dos significados em relação à perspectiva territorial do desenvolvimento é que, além da importância dos fatores econômicos para viabilizar um processo desse tipo, é imprescindível que a dinamização e condução do processo, seja construído a partir da participação ativa dos atores sócio-políticos locais, colocando no centro deste processo o bem-estar humano e recusando a supremacia econômica.

A noção de desenvolvimento territorial abre espaço para discutir o desenvolvimento rural e se coloca como um caminho na superação de práticas setoriais para a incorporação de práticas territorializadas (NAVARRO, 2001); por esta perspectiva, perdem sentido discussões 
sobre a dicotomia estabelecida entre urbano e rural. Esses dois elementos passam a caracterizar-se como indissociáveis em qualquer estratégia que vise desenvolver o território (NAVARRO, 2001; VEIGA, 2006).

No entanto, nem toda abordagem territorial leva em conta a fragilidade nas dinâmicas que se estabelecem entre grupos vulneráveis, empresas e Estado, que certamente guardam interesses divergentes. Para a aproximação da abordagem territorial à ATER faz-se necessário um olhar crítico sobre as concepções que entendem território como cooperação para competição; empreendedorismo coletivo; formação de sinergias, trustes, inovação, civismo e confiança. De outro modo, concebe-se território como processo social, com a existência de classes sociais, de luta de classes, de aperfeiçoamento da vida em sociedade, como nos indica Saquet (2011) ao trazer para a reflexão territorial as contribuições de Reclus, Lefebvre e Kaiser, concluindo que território pode ser entendido como produto de relações sociais, organizadas política e espacialmente.

Este entendimento de território tem a contribuir com o atual debate da ATER, mesmo que focado na redução da pobreza e nos segmentos da sociedade. Entretanto, embora o desenvolvimento territorial seja apontado como promissora abordagem alternativa a uma visão hegemônica de desenvolvimento que apresenta seus limites frente ao contexto de movimentos pelos quais a sociedade contemporânea se depara (aspectos ambientais, etc.), também a abordagem territorial apresenta seus limites, e por isso tem sido motivo de críticas.

Uma pesquisa denominada "Território e Desenvolvimento: a experiência de articulação territorial do Sudoeste do Paraná" realizada pelo Projeto de Cooperação Técnica FAO/MDA, revela que as práticas extensionistas mais citadas foram a assessoria à produção agropecuária e a elaboração de projetos de financiamento rural, respectivamente, por $64,7 \% \mathrm{e}$ $37,5 \%$ dos técnicos da região.

Pode-se perceber que há um "foco produtivista" na estratégia de ATER, na medida em que as ações na área educacional e de formação, de assessoria organizacional e de melhoria nas condições de moradia, saúde e alimentação não são tão valorizadas quanto às tarefas relacionadas à produção agrícola (TORRENS, 2007, p. 75).

\section{Torrens recomenda:}

Entretanto, além desses aspectos mais tradicionais da atuação dos profissionais de ATER/ATES, uma nova perspectiva de trabalho se impõe como uma dimensão central que precisa ser incorporada nas concepções, métodos e práticas coletivas das instituições governamentais e organizações sociais ligadas à agricultura familiar e à Reforma Agrária: trata-se da abordagem territorial [..]. Trata-se, principalmente, de se romper com a concepção eminentemente setorial que fundamenta o modo de pensar e agir de grande parte do corpo técnico que trabalha no meio rural. Nesse sentido, torna-se necessário implementar duas iniciativas complementares e interdependentes para que se avance na construção dessa perspectiva territorial: de um lado, é preciso reconhecer a urgência de se fortalecer os processos de integração dos instrumentos de política agrícola (crédito, assessoria técnica e extensão rural, pesquisa tecnológica, agroindustrialização, comercialização, associativismo e cooperativismo, agroecologia, aquisição de alimentos, diversificação produtiva), bem como de articular adequadamente esses instrumentos às políticas sociais (educação, saúde, previdência social, transferência de renda), de reordenamento agrário (Reforma Agrária, regularização fundiária, crédito fundiário), de incentivo à infraestrutura (estradas, comunicação, eletrificação, moradia, saneamento básico), de conservação sustentável dos ecossistemas e dos recursos naturais, de valorização 
cultural (artesanato, turismo rural, música) e de fortalecimento dos processos participativos de gestão social (TORRENS, 2007, p. 77, grifo nosso).

Ainda:

\begin{abstract}
De outro lado, faz-se necessário também integrar as ações que são desenvolvidas de forma fragmentada pelas diversas instituições, movimentos sociais e entidades não governamentais [...]. Para a concretização desse método de abordar o desenvolvimento torna-se necessário perceber, em primeiro lugar, que esse processo não é setorial, ou seja, baseado em ações restritas à dimensão agrícola do espaço rural. O segundo aspecto a superar decorre desse elemento anterior: para que seja efetivamente multidimensional, necessita-se de uma articulação de forças que não fique centralizada na agricultura familiar, entendida, na prática, como o sujeito político com capacidade de formular um projeto sustentável para o futuro das áreas rurais [...]. Atualmente, percebe-se ainda um grande distanciamento entre as políticas públicas implementadas no âmbito do MDA. Os diversos instrumentos e programas de política agrícola, agrária e de desenvolvimento territorial dialogam e interagem muito pouco entre si [...] (TORRENS, 2007, p. 78,79).
\end{abstract}

As conclusões que Torrens chega ao analisar o território sudoeste do Paraná guardam semelhanças às análises feitas por Abramovay (2007b), que apontam para uma política de ATER eminentemente setorial, como já citamos anteriormente. Também corroboram para esta reflexão os estudos de Sumpsi (2007) e Guanziroli (2012), embora o contexto observado não se refira especificamente à análise de ATER territorial.

Sumpsi (2007) vê a necessidade de adaptação do referencial Europeu para a América Latina, guardadas as diferenças de condições. Ainda ressalta que é enorme a distância que separa o conceito e a prática de desenvolvimento territorial. Sumpsi sumariza os problemas operativos que impedem o avanço do desenvolvimento territorial, onde constam: os critérios para definição dos territórios rurais; a relação público privado; as organizações locais; o plano estratégico; os instrumentos econômicos; o financiamento; os mecanismos de coordenação horizontal e vertical. O programa LEADER na América Latina encontraria muitos problemas, quais sejam: não há cultura nem experiência na relação público-privado e falta marco legal para transferência de recursos a ONGs; autoridades locais não valorizam espaços autônomos da sociedade civil; a cultura de projeto de desenvolvimento por mandato; os atores locais não tem autonomia de manejo dos fundos; não há recursos para manter a gestão do território e muito pouco para projetos produtivos. As diferenças de contexto para o desenvolvimento territorial entre UE e América Latina são notáveis. Na Europa tinha-se abundância de capital público e privado para a modernização rural; políticas de subsídios; mercado único e o pacto socialdemocrata para gerar emprego e renda. $\mathrm{Na}$ América Latina as políticas são de combate à pobreza. Assim como no programa LEADER, o Desenvolvimento Territorial Rural deve vir acompanhado de outras políticas públicas que, segundo autor, é o principal limite da América Latina.

Favareto (2010) analisa a efetivação prática da abordagem do desenvolvimento territorial. Questiona se, de fato, estaria ocorrendo uma mudança institucional ou seria apenas mais um termo usado junto com as velhas práticas de desenvolvimento. Sua conclusão é de que o desenvolvimento territorial corresponde a uma 'inovação por adição'. Ao analisar os documentos dos organismos bilaterais como o Banco Mundial e o BID, conclui que as inovações se dão por adição, ou seja, a superação das políticas setoriais é malograda ao aparecer como aplicação e não como estratégia. Nos instrumentos e nas orientações o viés é claramente produtivista e setorial. Além do que, o problema institucional aparece somente de

DRd - Desenvolvimento Regional em debate (ISSNe 2237-9029) 
forma dispersa. Analisando a capacidade do Estado, conclui que o mesmo tem apresentado dificuldade de operar com a mudança de paradigma contida na nova ruralidade.

Ortega e Mendonça (2007) e Guanziroli (2012), ao analisar os projetos a partir dos anos 70, que guardam alguma relação com este propósito, afirmam a dificuldade da abordagem territorial efetivar-se como uma alternativa viável. Tais projetos sofrem, de acordo com sua temporalidade, influências produtivistas liberais (ótima alocação; processo de globalização; acumulação flexível e descentralização) da "Terceira Itália", valorizando a diversidade econômica, social e política e das organizações da ONU (capital humano, desenvolvimento humano-IDH). Guanziroli (2012) afirma que a construção de um território é necessariamente lento. Esse é o limite que precisa ser superado e a solução não é só institucional. Sugere que quando as decisões locais estão amarradas a um conjunto de planejamentos predeterminados por onde vem os recursos, equivale a desistir da realidade local, sendo necessário inverter a lógica. Reconhecer a natureza do Estado é condição para as soluções mais duradouras e reais.

Pode-se pontuar que o desenvolvimento territorial constitui-se como uma ideologia que procura avançar sobre problemas em abordagens anteriores de desenvolvimento. Entretanto, dois elementos são centrais nas críticas colocadas: uma primeira linha diz respeito a um distanciamento entre o que prega a teoria do desenvolvimento territorial e sua implementação na prática, no caso das políticas públicas; a segunda linha de argumentação crítica vai ao sentido de que esse distanciamento tem origem na própria teoria que carece de consistência.

Por estas razões não surpreende que tanto a abordagem territorial quanto a nova ATER encontrem enormes dificuldades de operacionalização. Mesmo nos organismos multilaterais que sugerem tal abordagem aos países pobres, o fizeram apenas como adição aos velhos processos de desenvolvimento, como afirma Favareto (2010). No âmbito territorial, Torrens confirma os limites que já são percebidos em contextos maiores.

\section{A EFETIVA PROMOÇÃO DO DESENVOLVIMENTO TERRITORIAL NA ATER: UMA ANÁLISE}

Lima e Pinheiro (2010, p. 12) ao analisarem a atuação do governo federal na redefinição dos serviços de ATER, concluem que há uma espécie de "[...] repetição quase 'orquestrada' [...]', referindo-se ao fato de que no plano do discurso as políticas de Ater têm propósitos comuns, o que, entretanto, não se configura no plano das práticas, onde a ação extensionista apresenta certa ambiguidade "[...] ora sinalizando para um enfoque participativo com valorização dos saberes dos agricultores familiares, ora demonstrando grandes esforços para a captação de crédito por meio da elaboração de projetos de financiamentos nos pacotes tecnológicos". Embora não se reportem especificamente ao tema do desenvolvimento territorial, o resultado apresentado pelos autores sugere contradições entre a prática e a concepção.

Ao estudar a PNATER, Pettan (2010, p. 4) identifica que tal política sugere que a ação extensionista ocorra " $[. .$.$] no sentido de uma Ater participativa, construtivista, agroecológica e$ 
visando a sustentabilidade." Os resultados apontados pelo mesmo indicam a existência de limites e avanços pontuais na implementação dessa política. No que diz respeito aos propósitos desse artigo, o trabalho daquele autor referenda o fato do desenvolvimento territorial não ser um elemento central da PNATER.

Mais especificamente na temática da agroecologia, Mussoi (2011) aponta caminhos e descaminhos na ação extensionista no que diz respeito ao emprego efetivo de premissas agroecológicas presentes na PNATER. No âmbito da temática do desenvolvimento territorial, sua pesquisa sugere que a capacitação de gestores de projetos de desenvolvimento ainda é insuficiente para que tais projetos tenham êxito em incorporar aspectos elementares no contexto da agroecologia, onde a perspectiva de atuação territorial figura como estratégica.

[...] la capacitación de los directivos en todos los niveles, deja mucho a desear en el sentido de "dirigir" proyectos de desarrollo regionales, estaduales y mismo nacionales, que impliquen en gerenciar articulaciones con diversas otras entidades y sectores, dentro de una perspectiva interdisciplinar, intercultural, territorial, que impliquen en construcción de conocimientos (articulando el saber técnico-científico y el popular) y respecto a potencialidades locales (MUSSOI, 2011, p. 87, grifo nosso).

A prática dos atores de ATER também foi abordada em estudo conduzido por Deon (2015, p.98). Tomando por base empírica o município de Chapecó, o autor observou a contribuição destes atores para a dinâmica de formalização das Agroindústrias Familiares Rurais. Dentre os resultados importa resgatar a

[...] existência de 'comportamentos velados': parece haver uma 'atribuição de responsabilidade' por parte do ator de ATER em relação aos serviços prestados e que culminaram com a consolidação de determinado empreendimento, sugerindo interpretá-los como as agroindústrias 'da Epagri' ou as agroindústrias 'da Apaco' ou as agroindústrias 'do Saga'. Este comportamento revela a existência de um caminho ainda por trilhar, por parte destes atores, tendo em vista avançar para um 'pacto territorial'.

Embora o desenvolvimento territorial não seja o tema central do estudo realizado, essa passagem é empregada pelo autor em um contexto de análise com base em Abramovay (2000), para o qual os agricultores não seriam encarados pela sociedade local como protagonistas em vista de um possível "pacto territorial", reforçando a importância de lideranças e técnicos que os assessorem em engendrar ações coordenadas para a criação de um clima de confiança entre os atores locais. Neste sentido, quando comparadas, as práticas revelam que são desenvolvidas de forma fragmentada pela Epagri, a Apaco e pelo Instituto Saga ${ }^{9}$, ou seja, de acordo com Torrens (2007, p. 77), pouco contribuem para a abordagem territorial como uma nova perspectiva de trabalho "que precisa ser incorporada nas concepções, métodos e práticas coletivas das instituições governamentais e organizações sociais ligadas à agricultura

\footnotetext{
${ }^{9}$ A Empresa de Pesquisa Agropecuária e Extensão Rural de Santa Catarina (EPAGRI) é uma das principais referências em ações de ATER em Santa Catarina, não somente no que diz respeito às Agroindústrias Familiares Rurais, mas principalmente como executora oficial de políticas públicas para o meio rural no Estado; a Associação dos Pequenos Agricultores do Oeste Catarinense (APACO) constitui-se como uma Organização Não Governamental (ONG) e mobiliza um conjunto de ações de ATER, sendo uma organização com origens no meio sócio-cultural da agricultura familiar, coloca-se também como representante político deste público; o Instituto Saga constitui-se como uma Organização da Sociedade Civil de Interesse Público (OSCIP), também mobilizando ações de ATER no sentido de promover e acelerar o desenvolvimento socioeconômico regional do Estado de Santa Catarina.
}

DRd - Desenvolvimento Regional em debate (ISSNe 2237-9029) 
familiar".

Nos Documentos de referência da ATER, o termo desenvolvimento territorial é incorporado. Contudo, alguns limites podem ser notados. No texto da $1^{\text {a }}$ CNATER encontramos a afirmação a seguir que revela o entendimento de território que foi adotado.

\begin{abstract}
Promover e assegurar a participação ativa de todos/as os/as agentes de Ater e da sociedade civil organizada beneficiária nos espaços de debate, principalmente nos conselhos de desenvolvimento rural, no levantamento e qualificação das demandas, formulação, implementação, monitoramento e avaliação de políticas públicas voltadas para o desenvolvimento rural sustentável, nos níveis municipal, territorial, distrital, estadual, regional e nacional (BRASIL/MDA, 2012a, p. 24, grifo nosso).
\end{abstract}

Ou seja, o texto da conferência sugere que o território é apenas uma dimensão geográfica, física, sem superar a abordagem do desenvolvimento regional. No que diz respeito às políticas públicas implementadas pelo Ministério de Desenvolvimento Agrário, citamos duas: as políticas de desenvolvimento territorial e de assistência técnica e extensão rural (ATER). Enquanto uma é deliberadamente assumida como territorial, a outra faz poucas menções a tal abordagem. A "incorporação por adição" do termo "territorial" pode ser identificada no documento da CNATER, onde ocorre a incorporação de termos de diversos matizes teóricos, tão abertos que se perdem.

Teriam estas duas políticas orientações teóricas distintas? Seriam elas dissociadas de fato? Poderia um plano de desenvolvimento territorial determinar ações de ATER? Ainda que pese a aparente dissociação entre as políticas, como a abordagem territorial do desenvolvimento pode contribuir com o processo de transformação das práticas extensionistas?

Pergunta-se, ainda, se há uma fragilidade entorno da discussão territorial na PNATER e $1^{\text {a }}$ CNATER ou se tal problemática que se verifica na política de ATER não seria mais um reflexo do problema de concepção da própria abordagem territorial?

Estas questões vêm da percepção de que, mesmo depois de termos percorrido mais de trinta anos das críticas ao difusionismo e depois da adoção dos métodos dialógicos, participativos e agroecológicos enquanto diretrizes da política pública de ATER desde 2003, a elaboração do documento da $1^{\text {a }}$ CNATER e da criação da ANATER, a abordagem territorial não avançou como se esperava e ainda não é um caminho central e estratégico no que diz respeito à ação extensionista.

Em maio de 2014, criou-se a Agência Nacional de Assistência Técnica e Extensão Rural - ANATER. Esta tem como propósito a unificação das políticas e recursos para a Assistência Técnica e Extensão Rural. Avança-se desta forma na implantação do Sistema Brasileiro Descentralizado de Assistência Técnica e Extensão Rural - SIBRATER. No entanto, a criação da ANATER traz juntos outros sentidos. Está explícito nos materiais de divulgação da agência o casamento da pesquisa com a extensão rural, fato que no Brasil já apresentou dificuldades históricas. Nos documentos oficiais da ANATER, como no decreto de sua instituição, o termo territorial já não mais aparece. A estratégia de desenvolvimento rural que contemple problemas de natureza não agrícola, como sugere o debate territorial, não estaria sendo considerada, na medida em que a difusão das tecnologias produzidas nos centros de pesquisa é assumidamente a preocupação central.

No parágrafo único, do decreto do Executivo, $\mathrm{n}^{\circ}$ 8.252, que trata das competências

DRd - Desenvolvimento Regional em debate (ISSNe 2237-9029) 
estabelecidas, consta nos incisos II e V, que as atividades da ANATER deverão ser realizadas "em estreita colaboração com a Empresa Brasileira de Pesquisa Agropecuária - Embrapa" (D.O.U. DE 27/05/2014, P. 1). O inciso II trata da integração da pesquisa com a assistência técnica e a extensão rural, visando fomentar a geração de novas tecnologia e a adoção do conhecimento científico. $\mathrm{O}$ inciso $\mathrm{V}$ trata da formação continuada dos profissionais de assistência técnica e extensão rural.

Dois enfoques se fazem notar prioritariamente como orientadores: transferência de tecnologia e formação dos extensionistas. Um terceiro elemento que chama a atenção é a previsibilidade de monitoramento e avaliação. Nestes três quesitos, muito se assemelha a um antigo programa de extensão, denominado de Treino e Visita. A Embrapa publicou em 2007 um documento intitulado "Manual de Implantação do Treino e Visita (T\&V)" (DOMIT, 2007), seguido da publicação de um folder derivado da referida publicação intitulado "Capacitação contínua para transferência de tecnologia Treino e Visita".

Esta comparação sugere que a possibilidade da contribuição da abordagem territorial para a transformação das práticas de ATER assume os limites de velhas práticas de transferência de tecnologias, aqui no caso referido ao do Treino e Visita que é, de certa forma, retomado com vigor nas atribuições da ANATER, onde a Embrapa volta à cena da assistência técnica.

Treino e visita foi uma política evidentemente setorial. Contudo, já na Política Nacional de Assistência Técnica e Extensão Rural para a Agricultura Familiar e Reforma Agrária - PNATER (Lei No 12.188, de 11 de Janeiro de 2010), o termo desenvolvimento territorial já estava ausente. Desenvolvimento figura acompanhado de rural sustentável, fazendo alguma alusão à agroecologia.

A concepção teórico-metodológica do sistema de extensão Treino e Visita acreditava que as soluções para o rural seriam alcançadas desenvolvendo ao máximo as potencialidades produtivas das grandes culturas. Isso seria alcançado com a transferência de tecnologias das estações experimentais para os agricultores (BENOR; HARRISON; BAXTER 1984). Surpreendentemente, esta concepção está ressaltada nos documentos da ANATER. Treino e Visita consiste em abordagem para tornar mais efetiva a transferência de tecnologias. Para tanto, previa que o agricultor fosse intensivamente visitado. Para que o extensionista preste uma orientação de qualidade, este participa de formação, que é promovida pelo pesquisador. No aspecto da formação do extensionista previsto na ANATER, a semelhança é evidente.

No final dos anos 1960 e início de 1970, a difusão de tecnologia tornou-se o foco principal de sistemas de extensão agrícola. A pesquisa internacional tinha lançado variedades que estavam batendo recordes em produtividade e estas tinham sido adaptadas pelos sistemas nacionais de pesquisa. Ainda, neste meio tempo os preços dos alimentos estavam elevados devido à sua escassez. Haviam esforços para levar estas novas tecnologias aos agricultores mais receptivos. Mas a extensão rural da época era considerada pouco eficaz (BENOR; HARRISON; BAXTER 1984). A ANATER parece reviver este ideário e objetivo, pois é sua atribuição principal a transferência de tecnologias agropecuárias que existiriam com abundância nos centros de pesquisa.

A concepção de Treino e Visita como abordagem central da extensão foi desenvolvida no início de 1970, na Índia, em programas financiados pelo Banco Mundial. A percepção 
comum entre os políticos e autoridades agrícolas naqueles tempos era que o crescimento da produtividade agrícola fora constrangido pelo atraso do agricultor, organização inadequada e lideranças locais deficientes (BENOR; HARRISON; BAXTER 1984; ANDERSON, 2006). Avaliação semelhante hoje é direcionada aos projetos territoriais. Esta observação sugere que os fatos estão se repetindo, ou seja, que as tentativas localistas e polivalentes de desenvolvimento, a exemplo das territoriais, seriam um problema.

A abordagem territorial parece então promissora para a recriação dos serviços de ATER, se o passado fosse levado em conta. Entretanto, a relação entre a abordagem territorial do desenvolvimento e a ATER tem sido pouco discutida pela academia. Dentre as reflexões mais atualizadas podemos citar o Congresso da SOBER em 2009, realizado em Porto Alegre/RS, onde a temática foi abordada no painel sob o título "Extensão Rural e Desenvolvimento Territorial". O referido painel discutiu possíveis encontros entre estas duas propostas, nascidas no mesmo Ministério do Desenvolvimento Agrário - MDA. Nos documentos da SDT (Secretaria de Desenvolvimento Territorial) a abordagem territorial é densamente conceituada, ao contrário dos documentos referentes a ATER. A SDT se afina ao debate teórico, onde território não se limita a uma demarcação geográfica políticoadministrativa. No documento Programa Nacional de Desenvolvimento Sustentável de Territórios Rurais: referência para o apoio ao desenvolvimento territorial, o MDA assim define território:

\footnotetext{
Um espaço físico, geograficamente definido, geralmente contínuo, compreendendo cidades e campos caracterizados por critérios multidimensionais, tais como o ambiente, a economia, a sociedade, a cultura, a política e as instituições, e uma população com grupos sociais relativamente distintos, que se relacionam interna e externamente por meio de processos específicos, onde se pode distinguir um ou mais elementos que indicam identidade e coesão social, cultural e territorial (BRASIL/MDA, 2004b, p. 03).
}

No que pese à orientação operacional, o debate conceitual afina-se com alguns dos pressupostos territoriais. Entretanto, ressaltamos que embora o discurso político da SDT incorpore a noção de desenvolvimento territorial como sugere Brandão (2007), no campo da efetiva implementação essas políticas são alvo de críticas ${ }^{10}$.

Retomando sobre o painel realizado na SOBER 2009, este dava conta de ressaltar o resgate da ATER pública via PNATER e lembrar que "quase ao mesmo tempo" lançava-se a política de desenvolvimento territorial e portanto da necessidade da "efetiva" articulação das referidas políticas. Reconhecida como um grande desafio, representava mudanças na correlação de forças em todos os níveis de poder.

Diesel (2009, p. 12), em seu texto para aquele evento, pontua que o desenvolvimento territorial ao mesmo tempo em que se constitui como uma alternativa é, também, limitado, pois ' [...] a criação de instâncias territoriais de 'articulação' de políticas públicas tem sido apresentada como uma alternativa mas entende-se necessário considerar seu poder limitado [...]". Para chegar a essa consideração a autora faz uma leitura dos "desafios" que se colocam para a relação entre abordagem territorial e ATER, sob três enfoques: o desafio de "dar prioridade", o desafio de "dar significado", e o desafio de "qualificar" o processo.

Quanto ao desafio de dar prioridade, a autora argumenta que esse decorre de fatores

10Ver Balem; Silva; Froehlich (2013) sobre essa questão. 
que passam pela existência de uma espécie de inércia na atuação organizacional potencializada pela "interpretação local" decorrente de anos de atuação no meio rural, fato esse que acaba por criar obstáculos a novas abordagens, aos novos técnicos que tentam sair dessa condição.

Sua atuação neste meio, ao longo de sua história, acaba por gerar uma "interpretação local" sobre qual seria(m) seu(s) papel(s) e forma de atuação e determinar as expectativas e os comportamentos dos outros atores com quem interage[...]. As tentativas de sair deste padrão por parte de "técnicos recém chegados" ou programas governamentais inovadores geralmente enfrentam resistência [...] (DIESEL, 2009, p. 4).

Entretanto, essa dificuldade em priorizar a abordagem territorial também passa por uma questão de recursos. A autora aponta a dependência de recursos financeiros de diferentes origens como um fator que causa conflitos nas atribuições das organizações, o que inferimos também na atuação dos técnicos. Outra decorrência disso, no que concerne aos recursos públicos federais, atualmente os serviços de ATER têm sido implementados a partir de chamadas públicas para "[...] comprometimentos de prestação de serviços via licitação ou contrato cada vez mais ancorados em metas pré-determinadas" (DIESEL, 2009, p. 6). Abre-se um espaço aqui para refletir sobre dois desses documentos.

A chamada pública SAF/ATER $n^{\circ}$ 10/2012 que tem por objeto a "seleção de entidades para prestação de serviço de ATER destinado a agricultores e agricultoras familiares [...]" (BRASIL/MDA, 2012b, p. 5), é um documento atual e que serve como exemplo de como a atividade de ATER vem sendo direcionada por ações pontuais, com regras e metas bem delimitadas, onde a abordagem territorial não é tratada como um elemento central. Pelo contrário, a alusão a territórios refere-se a espaço geográfico. Já no Chamamento Público para Fomento a Projetos de Diversificação Econômica e Agregação de Valor na Agricultura Familiar, há menção à abordagem territorial nas diretrizes do documento que discorre sobre

[...] atuar em conjunto com as demais organizações no processo de desenvolvimento territorial, garantindo o desenvolvimento sustentável nos territórios selecionados pela Secretaria de Desenvolvimento Territorial e Territórios da Cidadania do Governo Federal (BRASIL/MDA, 2010, p. 7).

Nesse caso, o documento direciona os serviços contratados para uma atuação norteada pela abordagem territorial, que no discurso procura extrapolar a visão reducionista de território como simples espaço geográfico. Entretanto, voltamos aqui à crítica já colocada anteriormente sobre problemas de operacionalização para uma atuação articulada entre SDT e SAF/DATER, como o documento propõe.

Essa problemática que envolve a dependência de recursos públicos por parte das organizações de ATER "tradicionais" é apontada por Diesel (2009) como uma lacuna que tem contribuído para que ONGs (Organizações Não Governamentais), por sua flexibilidade, se apresentem como alternativas para a execução de políticas governamentais que incorporem a lógica territorial. Entretanto, mesmo para essas organizações a autora sugere outros tipos de entraves, relacionados à incompatibilidades na relação jurídico/operacional que envolve figuras jurídicas diferentes que são o poder público e as ONGs.

Quanto ao desafio de "dar significado", a autora coloca que haveria uma priorização do desenvolvimento territorial em aspectos econômicos, de inserção competitiva em mercados 
globalizados, ou seja, no sentido da crítica que argumentamos também nesse artigo, o desenvolvimento territorial como uma abordagem que ainda não conseguiu avançar na prática para atuação não setorial. A autora acrescenta ainda uma possibilidade de avanço nesse sentido com a aproximação do territorial com o desenvolvimento comunitário, mas ressalta que, com isso, ocorreria "abertura de foco", problema em potencial ao qual denomina "'esquizofrenia' do desenvolvimento territorial, na medida em que passa a ser constantemente criticado por sua seletividade temática e falta de legitimidade política" (DIESEL, 2009, p. 10).

Quanto ao desafio de "qualificar" a abordagem territorial, baseada em estudos empíricos sobre o quotidiano dos diferentes membros das famílias, os resultados remetem às múltiplas realidades vivenciadas por elas. Sua reflexão aponta para a existência de desconexão entre as múltiplas expectativas entre os atores da agricultura familiar e o que idealizam os agentes de desenvolvimento.

[...] em áreas de agricultura familiar parece existir uma produção e reprodução de expectativas com relação ao desejável e aceitável no modo de vida das famílias. Tais processos criam dinâmicas que parecem escapar "usualmente" às análises dos agentes de desenvolvimento, enquanto explicam o comportamento das famílias (DIESEL, 2009, p. 11).

Depois de alguns anos do referido painel, vale perguntar-se pelos desdobramentos visando identificar processos que se impõem atualmente ao debate. As chamadas públicas analisadas dão o tom de que os argumentos continuam atuais. É esclarecedora, nesse sentido, a obra organizada por Diesel; Neumann; Sá (2012) que reúne um conjunto de estudos sobre a extensão rural a partir de experiências com assentamentos da reforma agrária no RS. Sua atualidade nos dá uma noção de como a abordagem territorial vem sendo tratada no meio da extensão rural. Quanto à forma como a palavra território é utilizada nos textos, predomina a noção de território como espaço geográfico. As poucas vezes (2 encontradas) onde a palavra é mencionada com alusão à território, como sugere Brandão (2007), os autores o citam de modo a confirmar a crítica nesse artigo, ou seja, suas análises evidenciam um pluralismo de instituições de extensão rural com diferentes características e formas de atuação, agindo de forma descoordenada, apontando para a atuação setorial da extensão rural.

[...] ao mesmo tempo em que se observam iniciativas pioneiras de coordenação de agentes de ATER em nível territorial, cabe avançar na avaliação se estas indicam caminhos da passagem do pluralismo institucional a sistemas pluralistas. Observa-se que até mesmo o conhecimento das configurações institucionais da oferta de ATER nos diferentes territórios é deficiente (DIESEL, 2012, p. 54).

Para que se conformasse um sistema pluralista em cada microrregião haveria do Estado refletir sobre seu papel verificando a diversidade social encontrada, as demandas de orientação técnica, as organizações atuantes e seu potencial e como operar para cobrir as lacunas em direção à concretização de um projeto de desenvolvimento territorial democraticamente definido (LISBOA, 2012, p. 81).

O descompasso que afasta a concepção territorial de sua efetivação enquanto política pública pode ser percebida tanto nas políticas de ATER como nas políticas territoriais. Da mesma forma, os problemas para a integração entre dois campos de atuação sociotécnica e sociopolítica, mesmo se reconhecendo como necessário, parece indicar que os entraves são maiores que as condições para a sua efetivação, como bem antecipava o aludido painel sobre o tema realizado na SOBER 2009. 


\section{CONSIDERAÇÕES FINAIS}

Essa breve reflexão com base em documentos orientadores da ATER e em estudos sobre a temática do desenvolvimento territorial no contexto de atuação da extensão rural aponta para a constatação de que, predominantemente, a ação extensionista tem permanecido setorial, ficando evidente também a existência de descompasso entre o discurso e a prática. Percebe-se uma lacuna a ser preenchida pelo aprofundamento na teoria do desenvolvimento territorial, com seus limites e perspectivas, e a apropriação desses elementos pelo discurso e prática enquanto política pública de extensão rural.

A contribuição da Extensão Rural na construção social de territórios rurais, com base em trabalhos como os de Pettan (2010), Mussoi (2011) e Deon (2015), além dos documentos que orientam a ação extensionista, levanta a questão dos problemas que ainda se impõem, ou seja, problemas na atuação da ATER e na abordagem territorial em si. Diante do contexto analisado, argumentamos que a abordagem territorial do desenvolvimento constitui-se como referência com potencial para a renovação da ação de ATER; contudo, a existência de limites no seu próprio arcabouço teórico, o que têm contribuído para complexificar sua implementação enquanto política pública, demandam estudos e espaços que promovam o debate e a aproximação entre a academia e os atores da extensão rural e dos territórios.

É preciso fortalecer e retomar estes debates diante da observada renúncia da abordagem territorial enquanto estratégia efetiva de desenvolvimento, como se depreende da abordagem proposta por parte da ANATER, como se não houvesse um passado de críticas à lógica setorial. Estudos que busquem as razões disso se fazem necessários. Os desafios de "dar prioridade", de "dar significado", e de "qualificar", como antecipava Diesel no congresso da SOBER em 2009, talvez tenham se mostrado demasiadamente abstratos à época, contudo se apresentam bem atuais e podem ser interessantes pontos de partida para reflexões e conexões neste sentido. Cabe ressaltar que estudos desta natureza contribuem não só para reorientar a ação extensionista, mas para avançar na consolidação da própria abordagem territorial do desenvolvimento.

\section{REFERÊNCIAS}

ABRAMOVAY, R. Para uma teoria dos estudos rurais. In: ORTEGA, A.C.; ALMEIDA FILHO, N. (org.).Desenvolvimento Territorial, segurança alimentar e economia solidária. Campinas: Alínea Ed., p. 19-382007a.

. Estratégias alternativas para a extensão rural e suas consequências para o processo de avaliação. CONGRESSO DA SOBER, 45., 2007, Londrina. Texto apresentado nos debates sobre Assistência técnica e extensão rural no Brasil: Desafios para os Próximos Anos. Londrina: SOBER, 2007b. Disponível em: <www.econ.fea.usp.br/abramovay>. Acesso em: 07 set. 2012.

O capital social dos territórios: repensando o desenvolvimento rural. Economia Aplicada, v. 4, n. 2, p. 1-15, 2000. Disponível em: $<$ http://www.sep.org.br/artigo/ivcongresso66.pdf>. Acesso em: 30 jan. 2013. 
ANDERSON, J. R. The rise and fall of training and visit extension: an Asian mini-drama with an African epilogue.World Bank Publications, 2006.

BALEM, T.; SILVA, G. P.; FROEHLICH, J. M. Desenvolvimento Territorial no Brasil: uma análise desde o Território da Cidadania Central do Rio Grande do Sul. In $51^{\circ}$ Congresso da SOBER. Anais, Belém, 2013.

BENOR, Daniel ; HARRISON, J. Q. ; BAXTER, M. Agricultural Extension - The Training and Visit System. World Bank, Washington DC, USA, 1984.

BRANDÃO, C. Territórios com classes sociais, conflitos, decisões e poder. In: ORTEGA, A.C.; ALMEIDA FILHO, N. (Org.). Desenvolvimento territorial, segurança alimentar e economia solidária. Campinas: Alínea Ed., p. 39-61, 2007.

BRASIL. 2014. Lei n. ${ }^{\circ} 8.252$, de 26 de Maio de 2014. Institui o serviço social autônomo denominado Agência Nacional de Assistência Técnica e Extensão Rural - Anater. Diário Oficial da União. Ano CLI No- 99, Brasília - DF, terça-feira, p. 1, 27 de maio de 2014.

BRASIL/MDA - Ministério do Desenvolvimento Agrário. $1^{\text {a }}$ Conferência Nacional sobre Assistência Técnica e Extensão Rural na Agricultura Familiar e Reforma Agrária, $1^{\text {a }}$ CNATER. Relatório das propostas aprovadas na plenária final. Brasília: MDA, 2012a. Mimeo.

Chamada pública SAF/ATER $n^{\circ}$ 10/2012. Chamada pública para seleção de entidades executoras de assistência técnica e extensão rural para promoção da agricultura familiar sustentável. Brasília: MDA/SAF/DATER, 2012b. Disponível em: $<$ http://www.mda.gov.br>. Acesso em: 25 mar. 2013.

Chamamento Público para Fomento a Projetos de Diversificação Econômica e Agregação de Valor na Agricultura Familiar. Brasília: MDA/SAF/DATER, 2010. Disponível em: <http://www.mda.gov.br>. Acesso em: 25 mar. 2013.

Política Nacional de Assistência Técnica e Extensão Rural. Brasília: MDA/SAF/DATER, 2004a. Disponível em: <http://www.mda.gov.br>. Acesso em: 07 set. 2012.

Programa Nacional de Desenvolvimento Sustentável de Territórios Rurais: referência para o apoio ao desenvolvimento territorial. Brasília: MDA/SDT, 2004b. Mimeo.

CAPORAL, F. R.; COSTABEBER, J. A. Agroecologia e desenvolvimento rural sustentável: perspectivas para uma nova extensão rural. Agroecologia e Desenvolvimento Rural Sustentável. Porto Alegre, v. 1, n. 1, p. 16-37, jan./mar. 2000.

CAZZELA, A. As bases sociopolíticas do desenvolvimento territorial: uma análise a partir da experiência francesa. In: FROEHLICH, J. M. (Org.). Desenvolvimento territorial: produção, identidade e consumo. Ijuí: Ed. Unijuí, p. 15-52, 2012.

DEON, P. R. C. Ambiente institucional e agroindústrias familiares rurais: a contribuição dos atores na trajetória de formalização da atividade de processamento de alimentos e bebidas 
em Jaguari-RS e Chapecó-SC. 2015. Tese (Doutorado em Extensão Rural) - Universidade Federal de Santa Maria, Santa Maria, 2015. No prelo.

DIESEL, V. A construção de consensos sobre o futuro da extensão rural nas organizações de cooperação internacional. In: DIESEL, V.; NEUMANN, P. S.; SÁ, V. C. de (Orgs.).

Extensão rural no contexto do pluralismo institucional: reflexões a partir dos serviços de ATES aos assentamentos da reforma agrária no RS. Ijuí: Ed. Unijuí, p. 35-56, 2012.

Desenvolvimento territorial em busca de sua justificação e materialização: desafios para a extensão rural. 2009. In: $\mathbf{4 7}^{\mathbf{0}}$ Congresso da SOBER, Porto Alegre, 2009.

DOMIT, L. A. et al. Manual de implantação do treino e visita (T\&V). Embrapa Soja, 2007.

FAVARETO, A. A abordagem territorial do desenvolvimento rural - mudança institucional ou "inovação por adição"?. Estudos Avançados, v. 24, n. 68, p. 299-319, 2010.

Paradigmas do desenvolvimento rural em questão - do agrário ao territorial. 2006. Tese (Doutorado em Ciência Ambiental) - Universidade de São Paulo, São Paulo, 2006.

FIGUEIREDO, R. P. Extensão rural no Brasil: novos tempos. Revista Brasileira de Tecnologia. Brasília, v. 15, n. 4, p. 19-25, jul./ago. 1984.

GUANZIROLI, C. Desenvolvimento territorial rural no Brasil - uma polêmica. In: FROEHLICH, J. M. (org.). Desenvolvimento Territorial: produção, identidade e consumo. Ijuí: Ed. Unijuí, p. 203-224, 2012.

LIMA, M. A. A.; PINHEIRO, J. A. P. Extensão rural no Brasil: novos caminhos, novos desafios? In: CONGRESSO DA SOBER, 48., 2010, Campo Grande. Anais eletrônicos... Campo Grande: SOBER, 2010. Disponível em

$<$ http://www.sober.org.br/palestra/15/1015.pdf>. Acessoem: 30 jul. 2012.

LISBOA, R. da S. et al. Extensão rural do Rio Grande do Sul: evidências de configuração institucional pluralista? In: DIESEL, V.; NEUMANN, P. S.; SÁ, V. C. de (Orgs.). Extensão rural no contexto do pluralismo institucional: reflexões a partir dos serviços de ATES aos assentamentos da reforma agrária no RS. Ijuí: Ed. Unijuí, p. 57-82, 2012.

MUSSOI, E. M. Política de Extensión Rural Agroecológica en Brasil: avances y desafíos en la transición en las instituciones oficiales. 2011. Trabajo de investigación (Post Doctorado en Extensión Agroecológica) - Universidades Internacional de Andalucía y de Córdoba (España) y Universidad Federal de Santa Catarina (Brasil), Córdoba, 2011.

NAVARRO, Z. Desenvolvimento rural no Brasil: os limites do passado e os caminhos do futuro. Estudos Avançados, v. 15, n. 43, p. 83-100, 2001.

ORTEGA, A. C.; MENDONÇA, N. C. Estratégias de desenvolvimento territorial rural no Brasil: continuidades e rupturas. In: ORTEGA, A. C.; ALMEIDA FILHO, N. (Orgs.).

Desenvolvimento territorial, segurança alimentar e economia solidária. Campinas: Editora Alínea, p. 93-121, 2007.

PETTAN, K. B. A Política Nacional de Assistência Técnica e Extensão Rural (PNATER): 
percepções e tendências. 2010. Tese (Doutorado em Engenharia Agrícola) - Faculdade de Engenharia Agrícola, Universidade Estadual de Campinas, Campinas, 2010.

SAQUET, M. A. Por uma Geografia das territorialidades e das temporalidades: uma concepção multidimensional voltada à cooperação e para o desenvolvimento territorial. São Paulo: Outras Expressões, 2011.

SILVERMAN, D. Interpretação de dados qualitativos: métodos para análise de entrevistas, textos e interações. Porto Alegre: Artmed, 2009.

SUMPSI, J. M. Desarrollo rural com enfoque territorial: diferencias e semejanzas de las experiências de laUnión Europeia y América Latina. In: ORTEGA, A. C.; ALMEIDA FILHO, N. (Orgs.). Desenvolvimento Territorial, segurança alimentar e economia solidária. Campinas: Alínea Ed. , p. 63-91, 2007.

TORRENS, J. C. S. Território e desenvolvimento: a experiência de articulação territorial do Sudoeste do Paraná. Curitiba: Deser, 2007.

VEIGA, J. E. Nascimento de uma outra ruralidade. Estudos Avançados, São Paulo: USP, v. 20, n. 57, p. 333-353, 2006.

\section{Agradecimentos:}

Agradecemos à Profa. Vivien Diesel (PPG em Extensão Rural da UFSM) pela leitura e comentários críticos a este artigo, bem como às suas contribuições sobre a temática aqui abordada, devidamente referenciadas neste texto.

Artigo recebido em: 21/07/2015

Artigo aprovado em: 04/10/2015 